\title{
Deceased donor kidney transplant in a 70-year-old Jehovah's Witness patient: to transplant or not to transplant-a case report
}

\author{
Giselle Guerra $^{1,2}$, Mariella Ortigosa-Goggins ${ }^{1,2}$, Jeffrey J. Gaynor ${ }^{2,3}$, Gaetano Ciancio ${ }^{2,3,4}$ \\ ${ }^{1}$ Department of Medicine, Division of Nephrology, University of Miami Miller School of Medicine, Jackson Memorial Hospital, Miami, FL, USA; \\ ${ }^{2}$ Miami Transplant Institute, University of Miami Miller School of Medicine, Jackson Memorial Hospital, Miami, FL, USA; ${ }^{3}$ Department of Surgery, \\ University of Miami Miller School of Medicine, Jackson Memorial Hospital, Miami, FL, USA; ${ }^{4}$ Department of Urology, University of Miami Miller \\ School of Medicine, Jackson Memorial Hospital, Miami, FL, USA \\ Correspondence to: Gaetano Ciancio, MD. Department of Surgery and Urology, University of Miami Miller School of Medicine, Jackson Memorial \\ Hospital, Miami Fl., Miami Transplant Institute, 1801 NW $9^{\text {th }}$ Ave, $7^{\text {th }}$ Floor, Miami, FL 33136, USA. Email: gciancio@med.miami.edu.
}

\begin{abstract}
While Jehovah's Witness (JW) patients refuse transfusions of blood or blood products, they are willing to accept renal allograft transplantation. We describe here a case of what we believe is the oldest (a 70-year-old) JW candidate to undergo a deceased donor kidney transplant reported in the literature. Prior to transplantation, discussions ensued amongst the multidisciplinary transplant team, weighing the potential benefits $v s$. risks of performing a kidney transplant on this patient due to her refusal (due to religion) to accept any blood transfusions or blood products combined with her advanced age and having longstanding insulin-dependent, type 2 diabetes mellitus with extensive peripheral vascular disease. Preoperatively, we believed that the odds were in favor of performing the kidney transplant safely without the need for any blood product usage. However, her post-operative course was complicated by severe anemia, which developed by post-transplant day 4. The anemia incapacitated the patient's physical and psychological state, creating medical, social and financial burdens on the patient, family, medical team and hospital. Both family and patient grew concerned about her overall condition. Blood transfusion was offered in order to improve her weakness and shortness of breath that developed due to the severe anemia, but the patient (along with her family) refused such treatment. During the 17 days of hospitalization, it was a continuous struggle between the transplant team, patient, and family for her to continue with the recovery process; at times we had even considered that performing the transplant had been a mistake. While organ transplantation can be performed safely in Jehovah's Witnesses, there are multiple factors seen in this particular case that warrant analyzing: (I) the potential use of stricter transplant exclusionary criteria, given the recipient's advanced age and preexisting co-morbidities, which likely increased her risk of developing severe anemia post-operatively, and (II) the recipient's emotional/psychological post-operative state of high anxiety, which developed while she was experiencing the severe anemia; in hindsight, her anxiety level may have been reduced if we had offered daily post-operative psychological counseling sessions. While the patient's allograft is currently doing well, we probably did not have strict enough criteria for proper selection of a JW candidate for kidney transplantation.
\end{abstract}

Keywords: Deceased donor kidney transplant; Jehovah's Witness patient; potential benefits vs. risks of performing a kidney transplant; case report

Submitted Apr 27, 2020. Accepted for publication Aug 16, 2020.

doi: $10.21037 /$ atm-20-3593

View this article at: http://dx.doi.org/10.21037/atm-20-3593 


\section{Introduction}

The transplant community strongly believes that organ transplantation of lung, kidney, heart, and liver is the best solution or treatment option to improve quality of life and survival of patients experiencing end stage organ disease (1) including Jehovah's Witness (JW) patients (2). While Jehovah's Witness patients refuse transfusions of blood or blood products, they are willing to accept renal allograft transplantation (3). Severe anemia is a post-transplant surgical complication that can occur following kidney transplantation, and Jehovah's Witness patients need to be aware of the possibility of its occurrence and the existing difficulty in successfully treating them without using blood transfusions $(4,5)$.

We describe here the oldest (a 70-year-old) JW kidney transplant candidate that underwent deceased donor kidney transplantation reported in literature (5-7). Her postoperative course was complicated by the development of severe anemia, which incapacitated the patient's physical and psychological state, creating medical, social and financial burdens on the patient, family, medical team and hospital.

We hope that this case presentation will help readers to understand just how stressful the transplant process and development of an early post-transplant complication can be to the whole transplant team. Another goal of this case presentation is to address how we can possibly establish a better rapport with the transplant recipient and his/her family during this period in order to avoid a cumbersome situation. In this case presentation, the multi-disciplinary transplant team as well as the patient and her family were overwhelmed by the clinical situation, which interfered with the patient's overall plan of care. Fortunately, while this patient currently has ongoing allograft survival which remains excellent, it was nonetheless achieved at great cost.

We present the following article in accordance with the CARE reporting checklist (available at http://dx.doi. org/10.21037/atm-20-3593) (8).

\section{Case presentation}

A 70-year-old Jehovah's Witness (JW) female had end-stage renal disease (ESRD) caused by diabetic nephrosclerosis. She had multiple co-morbidities at time of transplant including: insulin-dependent, type 2 diabetes mellitus (DM) for approximately 40 years, high blood pressure for 6 years, and obesity with a weight of 79.4 kilos (BMI around 30). Her DM complications included peripheral vascular disease, retinopathy, and neuropathy, besides her known nephropathy. The patient started hemodialysis in May, 2017, dialyzing three times a week without any hemodynamic complications nor use of a midodrine. Prior to listing, her pre-transplant work-up did not reveal any coronary artery disease but a computed tomography angiography revealed extensive peripheral vascular disease (Figure 1). Her pre-operative $\mathrm{Hgb}$ was $10.9 \mathrm{~g} / \mathrm{dL}$. This patient was on the waitlist as of 12/27/2019 but accumulated time based on dialysis for 2.6 years prior. Fortunately, she received her first offer on $2 / 18 / 2020$ which led to her transplant.

The deceased donor kidney that was offered and transplanted came from a 41-year-old Caucasian male, with donation after cardiac death (DCD) and death due to head trauma. The donor's terminal creatinine was $1.0 \mathrm{mg} / \mathrm{dL}$; KDPI was $44 \%$. The right donor kidney was accepted for the transplant recipient, and the time zero biopsy (performed at the time of transplant) showed 7 glomeruli sclerosed out of 111 (6.3\%), no interstitial injury, mild acute tubular injury and no significant arteriolosclerosis. Prior to transplant the deceased donor kidney had been placed on hypothermic machine perfusion with excellent results: flow of 143 and resistance of 0.21 .

Prior to transplantation, discussions ensued amongst the multidisciplinary team members, surgical and medical, weighing the potential benefits $v s$. risks of performing the kidney transplant on this patient due to her refusal (due to religion) to accept any blood transfusions or blood products combined with her advanced age and having longstanding insulin-dependent, type 2 diabetes mellitus with extensive peripheral vascular disease. This case was presented to the high risk transplant selection committee. Decision to proceed prevailed as long as her hemoglobin at the time of transplant was optimal (i.e., $\mathrm{Hgb} \geq 10 \mathrm{~g} / \mathrm{dL}$ ). Based on reasonably good donor selection and health conditions optimized prior to surgery, final medical and surgical clearances were obtained. We believed that the odds were in favor of performing the kidney transplant safely without the need for any blood product usage.

The patient underwent a deceased donor kidney transplant on February 18, 2020 (during the COVID-19 pandemic) (9). COVID-19 testing of the donor was not performed due to initial screening and cause of death not being related to infection. During this time, OPOs were not regularly testing for COVID-19 due to lack of testing availability. During transplantation, no major complications were noted. The surgical procedure had a warm ischemia 

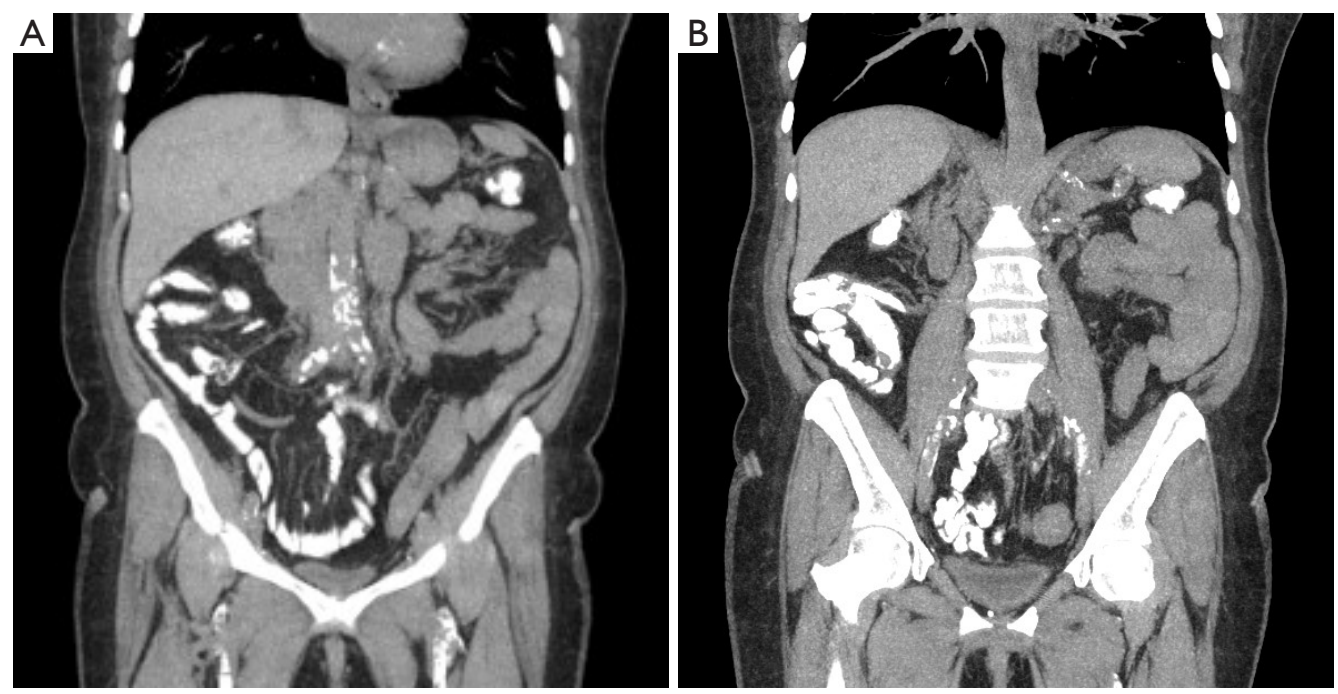

Figure 1 A pre-transplant computed tomography angiography of the patient revealed extensive peripheral vascular disease. (A) Extensive moderate atherosclerotic calcifications of the abdominal aorta (previously unpublished). (B) Extensive mild-to-moderate atherosclerotic calcifications of the common iliac arteries, right worse than left. Extensive mild-to-moderate atherosclerotic calcifications of the external iliac arteries (previously unpublished).

time of 30 minutes, and the estimated blood loss was only 75 cc. No surgical drainage nor ureteral stent were used. As a precaution, the cell saver was utilized; however, no sufficient blood loss was present to warrant its return back to the recipient. Desmopressin was given during the surgery to stimulate the release of von Willebrand Factor as given in other occasions with JW patients (2). Induction therapy included one dose of thymoglobulin $1 \mathrm{mg} / \mathrm{kg}$ and basiliximab $20 \mathrm{mg}$ given intravenously at the time of implantation (10). Immediately following the transplant procedure, the patient was transferred to the surgical intensive care unit in a stable hemodynamic condition for observation. She was then extubated promptly after 48 hours and was transferred to the transplant unit for ongoing post-operative care. A timeline of the patient's recovery post-transplant, including posttransplant serum creatinine and Hgb levels along with clinical commentary is shown in Table 1.

As per protocol, post-kidney transplant recipients with hemoglobin $\leq 10 \mathrm{~g} / \mathrm{dL}$ are placed on Epogen. This case was no different, as her Hgb had fallen below $10 \mathrm{~g} / \mathrm{dL}$ within 24 hours after the transplant was performed. She received Epogen $^{\circledR} 300 \mu / \mathrm{kg}$ daily for 15 days and intravenous iron $200 \mathrm{mg}$ for 5 days. However, despite minimizing intraoperative fluids and using pediatric tube phlebotomy, her Hgb had fallen over 35\% from her preoperative level by post-operative day 6 . There was a small complex fluid collection around $7 \mathrm{~cm}$ representing a hematoma anterior to the kidney based on imaging. On post-operative day 13 her creatinine was $1.49 \mathrm{mg} / \mathrm{dL}$ (Table 1). She was discharged home on post-operative day 17 without any significant surgical complications.

It's important to note that on post-op day 4, although the patient was clinically stable with good urine output and a serum creatinine level that was trending down slowly (Table 1), her Hgb level continued to decline. She became very weak, had problems ambulating and emotionally broke down not wanting to eat, drink or take her medications. Despite physical and emotional support given by the team and family, she clinically developed problems including shortness of breath, chest and abdominal pain. These symptoms were all attributed to severe anemia since all work-ups were negative for any pathology. Both family and patient grew concerned about her overall condition. Blood transfusion was offered in order to improve her weakness and shortness of breath, but the patient and her family both persistently refused treatment. Throughout 16 days of hospitalization, it was a continuous struggle between the transplant team, the patient and her family for her to continue with the recovery process; at times we even considered that performing the transplant on this patient had been a mistake.

Fortunately, at two months post-transplant the recipient has a creatinine of $0.72 \mathrm{mg} / \mathrm{dL}$. She also continues to get stronger; yet, her family is still very unsatisfied. They 
Table 1 Timeline of the patient's recovery post-transplant

\begin{tabular}{|c|c|c|c|}
\hline Time & Creatinine $(\mathrm{mg} / \mathrm{dL})$ & $\mathrm{Hgb}(\mathrm{g} / \mathrm{dL})$ & Comments \\
\hline Day $1(2 / 19 / 20)$ & 5.17 & 8.1 & \\
\hline Day $2(2 / 20 / 20)$ & 4.58 & 8.8 & \\
\hline Day $3(2 / 21 / 20)$ & 3.86 & 7.6 & $\begin{array}{l}\text { Patient maintains good urine output, and serum creatinine is trending } \\
\text { down slowly }\end{array}$ \\
\hline Day $5(2 / 23 / 20)$ & 2.63 & 7.2 & \\
\hline Day $6(2 / 24 / 20)$ & 1.95 & 6.8 & \\
\hline Day $8(2 / 26 / 20)$ & & & Patient has continued weakness and fatigue \\
\hline Day $9(2 / 27 / 20)$ & & & $\begin{array}{l}\text { Patient reports shortness of breath and pain in chest, upper arms and } \\
\text { forearms. Patient continues to feel very weak and tired }\end{array}$ \\
\hline Day $10(2 / 28 / 20)$ & 1.62 & 6.4 & \\
\hline Day $11(2 / 29 / 20)$ & & & $\begin{array}{l}\text { Patient reports feeling distinctly better, with more energy and an } \\
\text { improved appetite }\end{array}$ \\
\hline \multicolumn{4}{|l|}{ Day $12(3 / 1 / 20)$} \\
\hline Day $13(3 / 2 / 20)$ & 1.49 & 6.9 & \\
\hline \multicolumn{4}{|l|}{ Day $14(3 / 3 / 20)$} \\
\hline Month $1(3 / 19 / 20)$ & 0.90 & 10.9 & Outpatient Clinic Visit \\
\hline Month $2(4 / 15 / 20)$ & 0.72 & 11.2 & Outpatient Clinic Visit \\
\hline
\end{tabular}

continue to struggle with the patient's decision to receive the transplant due to her relatively lengthy hospital stay/ recovery phase. However, medically it's clear that she will likely have an improved quality of life and patient survival by remaining off dialysis.

All procedures performed for the single patient described in this case report were in accordance with our Institutional Review Board (IRB) and the Helsinki Declaration (as revised in 2013). Written informed consent was obtained from the patient for publication of this case report (as part of an overall clinical research protocol approved by the IRB at our center).

\section{Discussion}

Organ transplantation is a well-established treatment modality for organ failure even in higher risk patients such as Jehovah's Witnesses (2). This beneficial medical therapy is clearly evident in this group of patients when undergoing kidney transplantation versus remaining on dialysis as noted in overall patient survival outcomes $(5,7)$. To achieve the best results, an extensive pre-operative assessment of potential risk factors is essential (11), including presentation before a high risk selection committee as was done in this 
case. We are all aware that organ transplantation can be performed safely in Jehovah's Witnesses (2). However, in this particular case, there were two developing circumstances during the early post-transplant/recovery period that warrant discussion: (I) the recipient's advanced age and presenting co-morbidities, which likely increased her risk of developing severe anemia during the early posttransplant/recovery period, and (II) the recipient's unfolding emotional/psychological state that developed during that time, as both she and her family become highly anxious in response to the relatively long recovery period as a consequence of her severe anemia. Our attempts to alleviate the patient's condition as well as the family's concerns created a stressful environment which lasted throughout the patient's 17-day hospital stay.

While we performed a kidney allograft transplant in the oldest JW recipient reported in literature (5-7) safely, it is important to note the medical, social, and financial challenges it can bring. In hindsight, we agree with West (11). We probably did not have strict enough criteria for proper selection of a JW candidate for kidney transplantation, as the use of advanced age and/or comorbidity conditions as exclusionary criteria may be required for such transplant candidates in the future.

The article by West (11) states, "if the preoperative clinical status of the patient will mandate the use of blood products during the transplantation, then a JW patient should probably not be a candidate if he or she would refuse such transfusions" (11). In this particular case we felt comfortable that the transplant surgery could be performed without major perioperative complications. Still, we took various safety measures: (I) using cell-saver, (II) use of desmopressin, (III) minimizing induction therapy and intravenous fluids during the actual transplant, (IV) utilization of Epogen ${ }^{\circledR}$ and intravenous iron on the postoperative day one, (V) use of pediatric tube phlebotomy, (VI) close observation during the patient's SICU stay, and (VII) proper donor selection to almost guarantee immediate graft function (IGF). Despite optimal measures taken along with our best attempts to achieve IGF, the patient developed severe anemia as a post-operative complication $(2,5)$. Consequently, the patient and her family became righteously concerned and frustrated about the slow clinical improvement. The ongoing daily frustration expressed by the patient's family during her post-transplant hospital stay certainly contributed to the patient's increased anxiety level, and this situation certainly could have impeded the ongoing progress of the patient's care, even jeopardizing her graft outcome.
We are now struggling with this case and have more questions than answers. Should we perform a deceased donor kidney transplant into another 70 years old Jehovah's Witness candidate? During the pre-transplant process, the recipient and her family were all well informed about the complexity of the surgery and the specific peri- and post-operative complication risks that exist for a Jehovah's Witness candidate. Despite the extensive pre- and postoperative education given to the patient and her family as well as the intense multi-disciplinary medical care provided to the patient during the early post-transplant period, the family's expectations of a quick post-operative recovery differed from what had actually occurred.

One potential solution is for the mental health team of transplant psychologists/social workers to offer daily psychological counseling to the patient throughout the post-transplant hospital stay, possibly even starting this process before the patient receives the transplant. This way, a more preemptive and proactive approach would be taken towards reducing any patient anxiety and/or depression which may develop during this time.

It is more evident in cases such as these that make us wonder how we could have handled things differently. Our kidney transplant team and supporting medical staff have a history of transplanting for over 50 years, but challenging cases like these still present themselves. There are significant clinical, psychological, and financial burdens that must be taken into account. Not every transplant team has enough resources to provide ongoing education, staffing and ancillary services along with specialized units to help in the recovery of prolonged hospitalizations with JW recipients. Each transplant program needs to decide based on potential benefits versus risks of transplanting complex JW cases. What are they willing to accept and take on as a responsibility for these intended recipients and the program? Deceased organs are in scarce supply and should be transplanted to save lives and not to jeopardize the patient and/or the organ transplanted. These are very difficult medical and even ethical decisions to undertake in JW kidney transplant candidate selection, leaving us with the age old questionwhether to transplant or not to transplant?

\section{Acknowledgments}

Funding: None.

\section{Footnote}

Reporting Checklist: The authors have completed the CARE 
reporting checklist. Available at http://dx.doi.org/10.21037/ atm-20-3593

Conflicts of Interest: All authors have completed the ICMJE uniform disclosure form (available at http://dx.doi. org/10.21037/atm-20-3593). GC serves as an unpaid editorial board member of Annals of Translational Medicine from Nov 2019 to Oct 2021. The other authors have no conflicts of interest to declare.

Ethical Statement: The authors are accountable for all aspects of the work in ensuring that questions related to the accuracy or integrity of any part of the work are appropriately investigated and resolved. All procedures performed for the single patient described in this case report were in accordance with our Institutional Review Board (IRB) and the Helsinki Declaration (as revised in 2013). Written informed consent was obtained from the patient for publication of this case report (as part of an overall clinical research protocol approved by the IRB at our center).

Open Access Statement: This is an Open Access article distributed in accordance with the Creative Commons Attribution-NonCommercial-NoDerivs 4.0 International License (CC BY-NC-ND 4.0), which permits the noncommercial replication and distribution of the article with the strict proviso that no changes or edits are made and the original work is properly cited (including links to both the formal publication through the relevant DOI and the license). See: https://creativecommons.org/licenses/by-nc-nd/4.0/.

\section{References}

1. Tarabeih M, Bokek-Cohen Y, Azuri P. Health-related quality of life of transplant recipients: a comparison

Cite this article as: Guerra G, Ortigosa-Goggins M, Gaynor JJ, Ciancio G. Deceased donor kidney transplant in a 70-year-old Jehovah's Witness patient: to transplant or not to transplant-a case report. Ann Transl Med 2020;8(19):1249. doi: 10.21037/atm-20-3593 between lung, kidney, heart, and liver recipients. Qual Life Res 2020;29:1631-9.

2. Figueiredo RS, Thakkar RG, Ainley PR, et al. Review of abdominal solid organ transplantation in Jehovah's witness patients. World J Transplant 2019;9:94-102.

3. Panico ML, Jenq GY, Brewster UC. When a patient refuses life-saving care: issues raised when treating a Jehovah's Witness. Am J Kidney Dis 2011;58:647-53.

4. Gomez MF, Aljure O, Ciancio G, et al. Hemoglobin-based oxygen carrier rescues double-transplant patient from lifethreatening anemia. Am J Transplant 2017;17:1941-4.

5. Kaufman DB, Sutherland DER, Fryd DS, et al. A singlecenter experience of renal transplantation in thirteen Jehovah's Witnesses. Transplantation 1988;45:1045-9.

6. Hernández-Navarrete LS, Hernandez-Jimenez JD, Jimenez-Lopez LA, et al. Experience in kidney transplantation without blood transfusion: kidney transplantation transfusion-free in Jehovah's Witnesses. First communication in Mexico. Cir Cir 2013;81:450-3.

7. Boggi U, Vistoli F, Del Chiaro M, et al. Kidney and pancreas transplants in Jehovah's witnesses: ethical and practical implications. Transplant Proc 2004;36:601-2.

8. Gagnier JJ, Kienle G, Altman DG, et al., and the CARE Group. The CARE guidelines: consensus-based clinical case reporting guideline development. J Med Case Rep 2013:7:223.

9. Bogoch II, Watts A, Thomas-Bachli A, et al. Potential for global spread of a novel coronavirus from China. J Travel Med 2020;27;27.

10. Sageshima J, Ciancio G, Gaynor JJ, et al. Addition of antiCD25 to thymoglobulin for induction therapy: delayed return of peripheral blood CD25-positive population. Clin Transplant 2011;25:E132-5.

11. West JM. Ethical issues in the care of Jehovah's Witnesses. Curr Opin Anaesthesiol 2014;27:170-6. 